\title{
Triphala - An Indigenous Ayurvedic Mouthwash As An Anti-Inflammatory Agent - A Clinical Study
}

\author{
Dr. Shibam Chatterjee, ${ }^{1}$ Dr. Balaji Manohar, ${ }^{1}$ Dr. Neema Shetty, ${ }^{1}$ \\ Dr. Aditi Mathur, ${ }^{1}$ Dr. Barkha Makhijani ${ }^{1}$ \\ ${ }^{1}$ Department of Periodontics, Pacific Dental College and Hospital, Debari, Udaipur, India.
}

\begin{abstract}
Background: An antiplaque agent with minimal side effects that can be used as an effective adjunct to mechanical plaque control is needed. Mouthwash has been used for centuries for medicinal and cosmetic purposes, but in recent years, the rationale behind the use of chemical ingredients has been subjected to scientific research and clinical trials. Herbal medicines are in great demand in the developed as well as in developing countries for primary health care because of their wide biological and medicinal activities, higher safety margin, and lower costs. Triphala mouthwash used in Ayurveda since ancient times, is well-known for its anti-plaque, anti-gingivitis and anti-microbial properties.

Aim: To evaluate and compare the effects of an indigenously prepared $0.6 \%$ triphala mouthwash on dental plaque and gingival inflammation with a commercially available chlorhexidine mouthwash.

Materials and Methods: 20 subjects in the age group of 20-40 years with mild to moderate gingivitis were selected and divided into two equal groups in the study. Following oral prophylaxis, Group I $(\mathrm{n}=10)$ subjects were instructed to rinse with $10 \mathrm{ml}$ of $0.2 \%$ chlorhexidine mouthwash, Group II ( $\mathrm{n}=10$ ) subjects with $10 \mathrm{ml}$ of $0.6 \%$ triphala mouthwash twice daily for 14 days. Oral Hygiene Index-Simplified, TureskyGilmore-Glickman modification of Quigley-Hein-Plaque index and Gingival Index were recorded at baseline, 7 and 14 days respectively.

Results: Group I and Group II subjects showed statistically significant results in the reduction of the clinical parameters $(p<0.001)$. Group I subjects showed statistically significant results in reduction of the plaque status $(p<0.05)$ whereas; Group II subjects showed significant reduction in the gingival inflammation $(p<0.05)$.

Conclusion: Although, $0.2 \%$ chlorhexidine mouthwash yielded better results, $0.6 \%$ Triphala mouthwash may be used for short duration of time without any potential side-effects as an alternative to chlorhexidine mouthwash in reducing gingival inflammation.

Keywords: Chlorhexidine gluconate; plaque; triphala.
\end{abstract}

\section{INTRODUCTION}

Gingival and periodontal diseases appear to occur when pathogenic microbial plaque acts on a susceptible host. ${ }^{1}$ Supra-gingival plaque control is fundamental to the prevention and management of periodontal diseases, ${ }^{2}$ either mechanically or by means of different chemical agents. Mechanical plaque control becomes hazardous in patients who are medically compromised patients because of poor oral hygiene habits. Certain teeth surfaces receive minimum attention while tooth brushing. Thus, an adjunctive use of chemical agents has been practised. Chemical supragingival

\footnotetext{
Correspondence:

Dr. Shibam Chatterjee

Department of Periodontics,

Pacific Dental College and Hospital, Debari, Udaipur, India.

email: drshivamchatterjee@gmail.com

\section{Citation}

Chatterjee S, Manohar B, Shetty N, Mathur A, Makhijani B. Triphala - an indigenous ayurvedic mouthwash as an antiinflammatory agent - a clinical study. J Nepal Soc Perio Oral Implantol. 2017;1(2):60-4.
}

plaque control has been the subject of extensive research for the last 3 to 4 decades now. Various antimicrobial agents preventing the bacterial proliferation have been introduced recently. ${ }^{3}$ Chlorhexidine, a cationic bisbiguanide is gold standard among all mouthwashes, ${ }^{4-8}$ particularly because of its substantivity and broad-spectrum antibacterial activity. ${ }^{9-11}$ However; it has been reported to have a number of side effects like brown discoloration of teeth, salt taste perturbation, oral mucosal erosions and enhanced supragingival calculus formation, which limit its long-term use. .,12-14 $^{-1}$

Triphala is a combination of three medicinal plants, Amalaki Phyllanthus emblica (Emblica officinalis) Phyllanthaceae family, Haritaki (Terminalia chebula) Combretaceae family, and Bahera (Terminalia bellirica) Combretaceae family and has been extensively used in Ayurveda since ancient times. It helps in improving the body's immunity as it readily promotes antibodies against any invasion of antigens. ${ }^{15}$ Amalaki is an excellent source of vitamin $\mathrm{C}$ and also contains carotene, nicotinic acid, D-glucose, D-fructose, riboflavin, 
empicol, mucic and phyllemblic acids. Haritaki is used due to its broad spectrum of pharmacological activities which are associated with the biologically active chemicals present within the plant. It contains anthraquinone glycoside, chebulinic acid, tannic acid, terchebin, vitamin $\mathrm{C}$ and arachidonic, linoleic, oleic, palmitic and stearic acids. It inhibits the cell proliferation rate as well as cell death in the cancer cell line. Bahera contains chebulagic acid, ellagic acid and its ethyl ester, gallic acid, fructose, galactose, glucose, mannitol and rhamnose. ${ }^{16}$ The antioxidant activity of the extract was indicated by the reduction of lipid peroxide levels in wounds that were already treated. ${ }^{17}$ The dry fruits of these plants as well as triphala are easily available and are socioeconomic as well. Antioxidants present in triphala slow down the process of excess oxidation and protect cells from the damage caused by free radicals. ${ }^{18,19}$ Thus, the proven activity of these antioxidants is very helpful in modern medicine as well as for the treatment of diseases related with oxidative stress, particularly premalignant conditions. ${ }^{15,20}$ These antioxidants have also been scientifically proven to be safe and effective medicine against various oral health problems such as bleeding gums, halitosis, and mouth ulcers and for preventing tooth decay. One of the advantages of these natural herbs is that, no side effects of their use have been reported. ${ }^{21}$ Sushruta Samhita, in its 20th shloka, states that triphala can be used for gargling in dental diseases. Abraham $S$ et al. $^{22}$ reported the strong inhibitory activity of triphala against the polymorphonuclear leukocytes-type collagenases, particularly matrix metalloproteinase, ${ }^{9}$ and confirmed the use of triphala in periodontal diseases. Triphala has been reported to have antimicrobial, antiseptic, anti-inflammatory and antioxidant properties. . $^{16,17,23-25}$

The present study was undertaken to evaluate and compare the effects of an indigenously prepared $0.6 \%$ triphala mouthwash on dental plaque and gingival inflammation with a commercially available $0.2 \%$ chlorhexidine mouthwash.

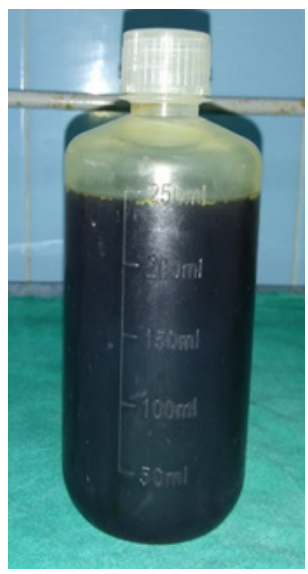

Figure 1: 0.6\% Triphala mouthwash.

\section{MATERIALS AND METHODS}

In this clinical study, 20 subjects $^{26}$ in the age group of 2040 years were enrolled from the out-patient Department of Periodontics. Before the commencement of this study, ethical clearance was obtained and informed consent from the subjects participating in this study was taken. The inclusion criteria included: subjects with chronic generalised gingivitis; mild to moderate gingivitis (Gingival Index of 1 to 2); no evidence of radiographic bone loss; no clinical attachment loss. The exclusion criteria included: use of any systemic antibiotics and anti-inflammatory drugs in the past 6 months; subjects with any systemic disease; orthodontic treatment or bridge work that would interfere with evaluation; allergy to ingredients used in the study; smoking habits; pregnant or lactating females and patient with poor compliance.

The subjects were divided into two equal groups: Group I ( $\mathrm{n}=$ 20) - Subjects using 0.2\% chlorhexidine mouthwash (Control group); Group II $(\mathrm{n}=20)$ - Subjects using 0.6\% triphala mouthwash (Test group). Before allocating the subjects to the groups, all underwent thorough scaling and root planing. The $0.6 \%$ triphala mouthwash was prepared by boiling 50 grams of triphala powder in 1 litre of water until it was reduced to $250 \mathrm{ml}$. After cooling, it was filtered with a strainer and this preparation was kept in a clean, sterilized bottle. The Group II subjects were advised to rinse with $10 \mathrm{ml}$ of this decoction as a mouthwash twice daily for 14 days. (Figure 1). The Group I subjects were advised to rinse twice daily with $10 \mathrm{ml}$ of commercially available $0.2 \%$ chlorhexidine mouthwash for 14 days.

The clinical parameters recorded were: Oral Hygiene IndexSimplified (OHI-S); Turesky-Gilmore-Glickman modification of Quigley-Hein-Plaque index and Gingival Index (GI) (Loe and Silness). The parameters were recorded at baseline, 7 and 14 days respectively. The statistical analysis for inter and intragroup comparison was done using Student's paired and unpaired 't' and one-way ANOVA (Analysis of Variance) tests. $p$ value of $<0.05$ was considered statistically significant.

\section{RESULTS}

A total of 20 subjects (9 males, 11 females) were selected for this clinical study. There were no drop-outs in the study.

The mean OHI-S scores in control group at baseline was $2.68 \pm 0.16$ which reduced to $1.20 \pm 0.13$ and $1.28 \pm 0.12$ after 7 and 14 days postoperatively respectively; which was significant ( $p$ value $<0.001$ ) when compared to the baseline (Table 1,2). The mean OHI-S scores from 7 to 14 days was also observed to be significant ( $p$ value $<0.001$ ) (Table 3 ). Whereas in the test group, the mean OHI-S scores at baseline 
Table 1: Comparison of effect of $0.2 \%$ chlorhexidine mouthwash and $0.6 \%$ triphala mouthwash on dental plaque and gingival inflammation from baseline to 7 days.

\begin{tabular}{|c|c|c|c|c|c|c|c|}
\hline \multirow{2}{*}{} & \multicolumn{2}{|c|}{ Group I (Control) } & \multicolumn{3}{c|}{ Group II (Test) } \\
\cline { 3 - 9 } & OHI-S & PI & GI & OHI-S & PI & GI \\
\hline Baseline & Mean \pm SD & $2.68 \pm 0.16$ & $2.68 \pm 0.22$ & $1.88 \pm 0.12$ & $2.68 \pm 0.16$ & $2.73 \pm 0.73$ & $1.81 \pm 0.17$ \\
\hline 7days & Mean \pm SD & $1.20 \pm 0.13$ & $1.36 \pm 0.12$ & $1.63 \pm 0.12$ & $1.37 \pm 0.14$ & $1.48 \pm 0.14$ & $1.72 \pm 0.20$ \\
\hline & $p$ value & $<0.001 \mathrm{HS}$ & $<0.001 \mathrm{HS}$ & $<0.001 \mathrm{HS}$ & $<0.001 \mathrm{HS}$ & $<0.001 \mathrm{HS}$ & $<0.001 \mathrm{HS}$ \\
\hline
\end{tabular}

Table 2: Comparison of effect of $0.2 \%$ chlorhexidine mouthwash and $0.6 \%$ triphala mouthwash on dental plaque and gingival inflammation from baseline to 14 days.

\begin{tabular}{|c|c|c|c|c|c|c|c|}
\hline \multirow{2}{*}{} & \multicolumn{2}{c}{} & \multicolumn{3}{c|}{ Group I (Control) } & \multicolumn{3}{c|}{ Group II (Test) } \\
\cline { 3 - 8 } & & OHI-S & PI & GI & OHI-S & PI & GI \\
\hline Baseline & Mean \pm SD & $2.68 \pm 0.16$ & $2.68 \pm 0.22$ & $1.88 \pm 0.12$ & $2.68 \pm 0.16$ & $2.73 \pm 0.73$ & $1.81 \pm 0.17$ \\
\hline 14 days & Mean \pm SD & $1.28 \pm 0.12$ & $1.42 \pm 0.14$ & $1.70 \pm 0.13$ & $1.46 \pm 0.15$ & $1.60 \pm 0.15$ & $1.68 \pm 0.21$ \\
\hline & $p$ value & $<0.001 \mathrm{HS}$ & $<0.001 \mathrm{HS}$ & $<0.001 \mathrm{HS}$ & $<0.001 \mathrm{HS}$ & $<0.001 \mathrm{HS}$ & $<0.001 \mathrm{HS}$ \\
\hline
\end{tabular}

Table 3: Comparison of effect of $0.2 \%$ chlorhexidine mouthwash and $0.6 \%$ triphala mouthwash on dental plaque and gingival inflammation from 7 days to 14 days.

\begin{tabular}{|c|c|c|c|c|c|c|c|}
\hline \multirow{2}{*}{} & \multicolumn{2}{|c|}{ Group I (Control) } & \multicolumn{3}{c|}{ Group II (Test) } \\
\cline { 3 - 9 } & & OHI-S & PI & GI & OHI-S & PI & GI \\
\hline 7 days & Mean \pm SD & $1.20 \pm 0.13$ & $1.36 \pm 0.12$ & $1.63 \pm 0.12$ & $1.37 \pm 0.14$ & $1.48 \pm 0.14$ & $1.72 \pm 0.20$ \\
\hline 14 days & Mean \pm SD & $1.28 \pm 0.12$ & $1.42 \pm 0.14$ & $1.70 \pm 0.13$ & $1.46 \pm 0.15$ & $1.60 \pm 0.15$ & $1.68 \pm 0.21$ \\
\hline & $p$ value & $<0.001 \mathrm{HS}$ & $<0.05 \quad \mathrm{~S}$ & $<0.001 \mathrm{HS}$ & $<0.001 \mathrm{HS}$ & $<0.001 \mathrm{HS}$ & $<0.05 \mathrm{~S}$ \\
\hline
\end{tabular}

Table 4: Intergroup comparison between $0.2 \%$ chlorhexidine mouthwash and $0.6 \%$ triphala mouthwash at baseline, 7 days and 14 days.

\begin{tabular}{|c|c|c|c|}
\hline \multirow{2}{*}{} & \multicolumn{2}{|c|}{$\mathbf{p}$ value (Test/control) } \\
\cline { 2 - 4 } & OHI-S & PI & GI \\
\hline Baseline & $1.00 \mathrm{NS}$ & $0.57 \mathrm{NS}$ & $0.30 \mathrm{NS}$ \\
\hline 7 days & $0.65 \mathrm{NS}$ & $0.47 \mathrm{NS}$ & $0.23 \mathrm{NS}$ \\
\hline 14 days & $0.25 \mathrm{NS}$ & $0.35 \mathrm{NS}$ & $0.83 \mathrm{NS}$ \\
\hline
\end{tabular}

was $2.68+0.16$ which reduced to $1.37 \pm 0.14$ and $1.46 \pm 0.15$ after 7 and 14 days postoperatively respectively; which was seen to be significant ( $p$ value $<0.001$ ) when compared to the baseline (Table 1, 2). The mean OHI-S scores from 7 to 14 days was also significant ( $p$ value $<0.001$ ) (Figure 2, Table 3 ). When the mean OHI-S scores at baseline ( $p$ value $=1.00$ ) was compared to 7 days ( $p$ value $=0.65$ ) and 14 days postoperative scores ( $p$ value $=0.25$ ) between the two groups, the difference was found to be non-significant (Table 4).

The mean PI scores of control group at baseline of $2.68 \pm$ 0.22 which reduced to $1.36 \pm 0.12$ and $1.42 \pm 0.14$ after 7 and 14 days postoperatively respectively; which was significant ( $p$ value $<0.001$ ) when compared to the baseline (Table 1 \& 2 ). The mean PI scores from 7 days to 14 days were seen to be significant ( $p$ value $<0.05$ ) (Table 3 ). The mean PI scores of $2.73+0.73$ of test group at baseline reduced to $1.48 \pm$ 0.14 and $1.60 \pm 0.15$ after 7 and 14 days postoperatively respectively; which was significant ( $p$ value $<0.001$ ) when compared to the baseline (Table $1 \& 2$ ). The mean PI scores from 7 to 14 days was also significant ( $p$ value $<0.001$ )
(Figure 3, Table 3). When the mean PI scores at baseline ( $p$ value $=0.57)$ was compared to 7 days $(p$ value $=0.47)$ and 14 days post-operative scores ( $p$ value $=0.35$ ) between the two groups, the difference was found to be non-significant (Table 4).

The mean GI scores of control group at baseline was $1.88 \pm 0.12$ which reduced to $1.63 \pm 0.12$ and $1.70 \pm 0.13$ after 7 and 14 days postoperatively respectively; which was seen to be significant ( $p$ value $<0.001$ ) when compared to the baseline (Table 1, 2). The mean GI scores from 7 to 14 days was significant ( $p$ value $<0.001$ ) (Table 3 ). The mean GI scores of test group at baseline was $1.81 \pm 0.17$ which reduced to $1.72 \pm 0.20$ and $1.68 \pm 0.21$ after 7 and 14 days postoperatively respectively; which was also significant ( $p$ value $<0.001$ ) when compared to the baseline (Table 1, 2). The mean GI scores from 7 to 14 days was significant $p$ value $<0.05$ ) (Table 3 ). When the mean Gingival index scores at baseline ( $p$ value $=0.30$ ) was compared to 7 days ( $p$ value $=0.23$ ) and 14 days postoperative scores ( $p$ value $=0.83$ ) between the two groups, the difference was found to be non-significant (Figure 4, Table 4). 
Figure 2: Oral Hygiene Index - Simplified Score.

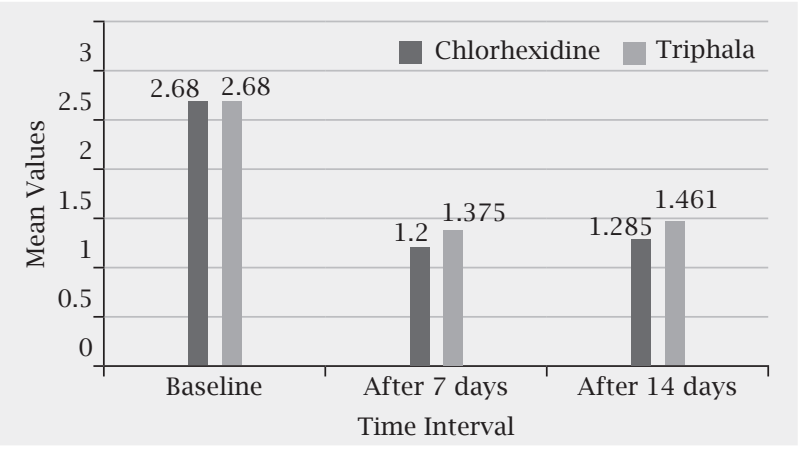

Figure 4: Gingival Index Score.

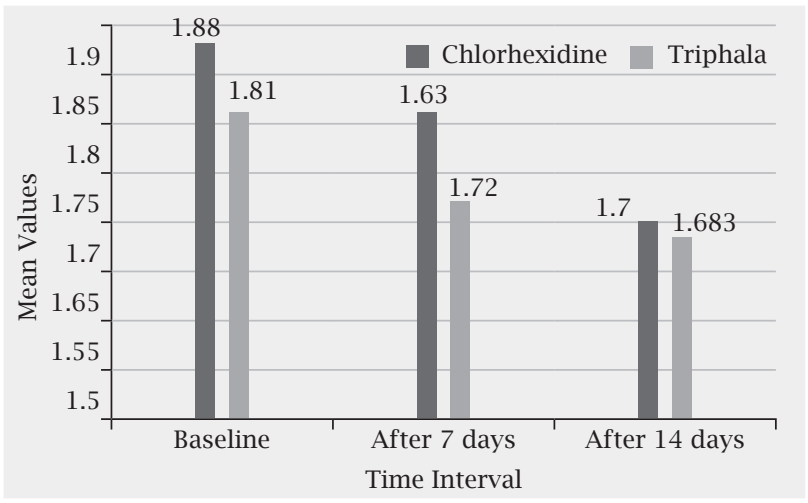

\section{DISCUSSION}

The present clinical study was done to evaluate the efficacy of $0.6 \%$ triphala mouthwash and to compare it with $0.2 \%$ chlorhexidine mouth rinse on oral hygiene status, plaque accumulation and gingival inflammation. Study participants were randomly allocated into two groups. Clinical examination was done to record plaque and gingival scores at baseline and post-rinsing according to the study by Bajaj et al. ${ }^{27}$ The purpose of recording was to observe any soft tissue changes such as increase or decrease in inflammation occurring due to the use of agent. Plaque and gingival scores were recorded for all participants at baseline, 7 days and 14 days post-operatively. The effect of triphala extract mouth rinse was intended to be studied in a real life situation and pre-operative oral prophylaxis was performed. This is in accordance with the study conducted by Chainani SH et al. ${ }^{28}$

Tiphala has been used as a mouth rinse in healthy, gingivitis and periodontitis patients. ${ }^{29,30}$ Triphala presented an antiplaque efficacy similar to that of chlorhexidine and was more effective in inhibiting plaque formation with lesser or no side effects. ${ }^{31}$

Sushruta Samhita has emphasized that triphala has hemostatic, anti-inflammatory, analgesic, and wound healing properties. Haritaki is the most efficacious for bleeding gums and gingival ulcers as well as carious teeth. On the other hand, Amalaki contains a large amount of vitamin C, which is very effective in preventing bleeding from gums. ${ }^{32}$

Jagadish L et al. ${ }^{29}$ conducted a study to determine the effect of triphala on dental biofilms and concluded that triphala had
Figure 3: Plaque Index Score.

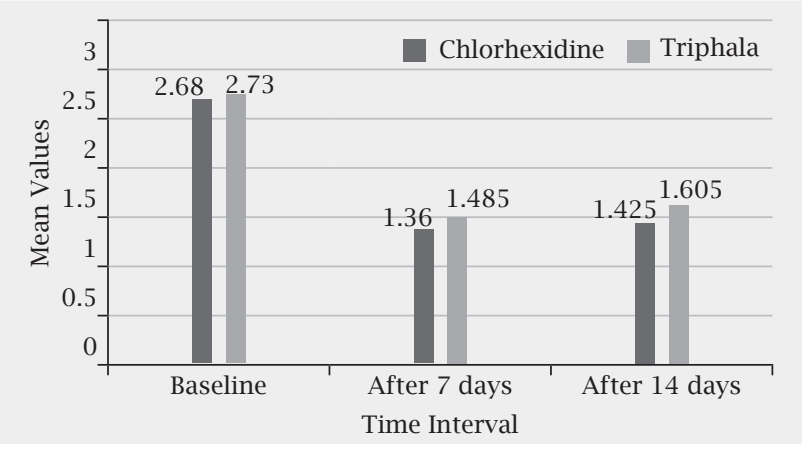

potent antioxidant and antimicrobial activity and inhibited the growth of Streptococcus mutans and gram-positive cocci involved in plaque formation when it was adsorbed on the tooth surface. Bhattacharjee $\mathrm{R}$ et $\mathrm{al}^{33}$ conducted a study to evaluate the efficacy of triphala mouth rinse (aqueous) in the reduction of plaque and gingivitis among children and concluded that both chlorhexidine and triphala groups showed significantly lower mean GI and PI scores at followup than baseline $(p<0.001)$ and no significant difference in the percentage change in the mean GI scores between the two groups ( $p=0.82$ ). The percentage change in the mean plaque index scores was significantly higher in the chlorhexidine group compared to the triphala group ( $p=0.048$ ). In our study, the percentage change in mean plaque $(p=0.35)$ and gingival index scores $(p=0.83$ ) between the two groups was statistically non-significant. Tandon $\mathrm{S}$ et al. ${ }^{34}$ suggested the use of triphala mouthwash for preventing the development of incipient lesions and reported that triphala mouthwash is cheaper than the commercially available chlorhexidine mouthwash. Being an ayurvedic product, it has no side effects and hence is safer for long-term use.

Effectiveness of chlorhexidine can be attributed to its bactericidal and bacteriostatic effects and its substantivity within the oral cavity ( 8 hours after rinsing). In group using $0.2 \%$ chlorhexidine mouthwash, the mean difference in OHI-S, PI and GI scores from baseline to 14 days postoperatively were $1.28 \pm 0.12 ; 1.42 \pm 0.14$ and $1.7 \pm 0.13$ respectively which was significant $(\mathrm{p}<0.001)$. In group using $0.6 \%$ Triphala mouthwash, the mean difference in OHI-S, PI and GI scores from baseline to 14 days post-operatively were $1.46 \pm 0.15 ; 1.60 \pm 0.15$ and $1.68 \pm 0.21$ respectively which was statistically significant $(\mathrm{p}<0.001)$. This is in accordance with the study conducted by Moran J et al. ${ }^{35}$ and Quiren M36 in which chlorhexidine was found to be effective in reducing plaque and gingival scores.

\section{CONCLUSION}

Triphala is a novel drug with an array of therapeutic effects gifted by Ayurveda to the world. It has potential to treat a variety of human ills with minimal or no side-effects. Dentistry is still in search of a drug for diseases affecting hard and soft tissues of oral cavity. Triphala seems to fulfil most of these requirements without any adverse effect 
on oral tissues and at very minimal cost as compared to commercially available products today.

Although, chlorhexidine mouthwash yielded better results than the triphala mouthwash in the present study, the latter may be used for short-term duration without any potential side-effects as an alternative to chlorhexidine in reducing gingival inflammation. Triphala can be used as a mouthwash in conjunction with scaling and root planing. Further studies are required with larger sample size to evaluate the long term effects of triphala as a mouthwash.

\section{REFERENCES}

1. Haffajee AD, Socransky SS. Microbial etiological agents of destructive periodontal diseases. Periodontol 2000. 1994;5:78-111.

2. Axelsson P. In: Lang N, Karring T, editors. Mechanical plaque control: Proceedings of the 1st European workshop on periodontics, 1993; London: Quintessence; 1994. Page 219-43.

3. Eley BM. Antibacterial agents in the control of supragingival plaque: a review. Br Dent J. 1999;186(6):286-96.

4. Nagappan N, John J. Antimicrobial efficacy of herbal and chlorhexidine mouth rinse: a systematic review. J Dent Med Sci. 2012;2:5-10.

5. Addy M, Moran JM. Evaluation of oral hygiene products: science is true; don't be misled by the facts. Periodontol 2000. 1997;15:40-51.

6. Asadoorian J. CDHA Position Paper on Commercially Available Over-the-Counter Oral rinsing Products. Can J Dent Hyg. 2006;40(4):168-83.

7. Loe $\mathrm{H}$, Schiott CR. The effect of mouthrinses and topical application of chlorhexidine on the development of dental plaque and gingivitis in man. J Periodontal Res. 1970;5:79-83.

8. Imfeld T. Chlorhexidine-containing chewing gum. Clinical documentation. Schweiz Monatsschr Zahnmed. 2006;116:476-83.

9. Van Leewen MP, Slot DE, Van der Weijden GA. Essential oils compared to chlorhexidine with respect to plaque and parameters of gingival inflammation: a systematic review. J Periodontol. 2011;82(2):174-94.

10. Rolla G, Loe H, Schiott CR. Retention of chlorhexidine in the human oral cavity. Arch Oral Biol. 1971;16:1109-16.

11. Adams D, Addy M. Mouthrinses. Adv Dent Res. 1994;8(2):291-301.

12. Flotra L, Gjermo P, Rolla G, Waerhaug J. Side effects of chlorhexidine mouth washes. Scand J Dent Res. 1971;79:119-25.

13. Overholser CD. Longitudinal clinical studies with antimicrobial mouthrinses. J Clin Periodontol. 1988;15:517-19.

14. Addy M. Chlorhexidine compared with other locally delivered antimicrobials: a short review. J Clin Periodontol. 1986;13:957-64.

15. Bose S, Sinha SK, Mukherjee G. In-vitro study of triphala on antioxidant activity. Sci Cult. 2011;77:511-13.

16. Surya Prakash DV, Sree Satya N, Avanigadda S, Vangalapati M. Pharmacological review on Terminalia chebula. Int J Res Pharm Biomed Sci. 2012;3:679-83.

17. Dar PA, Sofi G, Parray SA, Jafri MA. Halelah siyah (Terminalia chebula retz): in unani system of medicine and modern pharmacology: a review. Int J Inst Pharm Life Sci. 2012;2:138-49.

18. Vani T, Rajani M, Sarkar S, Shishoo CJ. Antioxidant properties of the Ayurvedic formulation Triphala and its constituents. Pharm Biol. 1997;35:313-17.

19. Padmawar A, Bhadoriya U. Phytochemical investigation and comparative evaluation of in vitro free radical scavenging activity of Triphala \& Curcumin. Asian J Pharm Med Sci. 2011;1:9-12.

20. Ariyaphong W, Kanjana J, Seewaboon S. Triphala: The Thai traditional herbal formulation for cancer treatment. Songklanakarin J Sci Technol. 2009;31:139-49.

21. Malhotra R, Grover V, Kapoor A, Saxena D. Comparison of the effectiveness of a commercially available herbal mouthrinse with chlorhexidine gluconate at the clinical and patient level. J Indian Soc Periodontol. 2011;15:349-52.

22. Abraham S, Kumar MS, Sehgal PK, Nitish S, Jayakumar ND. Evaluation of the inhibitory effect of triphala on PMN-type matrix metalloproteinase (MMP-9) J Periodontol. 2005;76:497-502.

23. Desai A, Anil M, Debnath S. A clinical trial to evaluate the effects of triphala as a mouthwash in comparison with chlorhexidine in chronic generalised periodontitis patient. Indian J Dent Adv. 2010;2:243-7.

24. Thomas B, Shetty SY, Vasudeva A, Shetty V. Comparative evaluation of antimicrobial activity of triphala and commercially available toothpastes: an in-vitro study. Int J Public Health Dent. 2011;2:8-12.

25. Biradar YS, Jagatap S, Khandelwal KR, Singhania SS. Exploring of antimicrobial activity of triphala, Mashi- an ayurvedic formulation. Evid Based Complement Alternat Med. 2008;5:107-13.

26. Mamgain P, Kandwal A, Mamgain RK. Comparative evaluation of triphala and ela decoction with $0.2 \%$ chlorhexidine as mouthwash in the treatment of plaque-induced gingivitis and halitosis: a randomized controlled clinical trial. J Evid Based Complementary Altern Med. 2017;22(3):468-72.

27. Bajaj N, Tandon S. The effect of triphala and chlorhexidine mouthwash on dental plaque, gingival inflammation, and microbial growth. Int J Ayurveda Res. 2011;2:29-36.

28. Chainani SH, Siddana S, Reddy CV, Manjunathappa TH, Manjunath M, Rudraswamy S. Antiplaque and antigingivitis efficacy of triphala and chlorhexidine mouth rinse among school children - a cross over, double blind - randomised controlled trial. Oral Health Prev Dent. 2014;12:209-17.

29. Jagadish L, Anand Kumar VK, Kaviyarasan V. Effect of Triphala on dental biofilm. Indian J Sci Technol. 2009;2:30-3.

30. Bonesvoll P, Lökken P, Rölla G, Paus PN. Retention of chlorhexidine in the human oral cavity after mouth rinses. Arch Oral Biol. 1974;19:209-12.

31. Bozkurt FY, Oztürk M, Yetkin Z. The effects of three oral sprays on plaque and gingival inflammation. J Periodontol. 2005;76:1654-60.

32. Maurya DK, Mittal N, Sharma KR, Nath G. Role of triphala in the management of peridontal disease. Anc Sci Life. 1997;17:120-7.

33. Bhattacharjee R, Nekkanti S, Kumar NG, Kapuria K, Acharya S, Pentapati KC. Efficacy of triphala mouth rinse (aqueous extracts) on dental plaque and gingivitis in children. J Investig Clin Dent. 2015;6:206-10.

34. Tandon S, Gupta K, Rao S, Malagi KJ. Effect of triphala mouthwash on the caries status. Int J Ayurveda Res. 2010;1:93-9.

35. Moran J, Pal D, Newcombe R, Addy M. Comparison of a phenolic and a $0.2 \%$ chlorhexidine mouthwash on the development of plaque and gingivitis. Clin Prev Dent. 1991;13:31-5.

36. Quirynen M, Avontroodt P, Peeters W, Pauwels M, Coucke W, Van Steenberghe D. Effect of different chlorhexidine formulations in mouthrinses on de novo plaque formation. J Clin Periodontol. 2001;28:1127-36. 